\title{
Afetler Karşısında Toplum Dirençliliği
}

\author{
Nehir VAROL ${ }^{1 *}$, Esma BULUŞ KIRIKKAYA ${ }^{2}$
}

\section{Öz}

Afetler günlük yaşamı alt üst eden, can ve mal kayıplarına yol açabilen, insan çevre arasındaki dengenin bozulmasına neden olan olaylardır. Doğal ya da teknolojik tehlike, risk ve kırılganlık ile birleştiğinde yıkıcı afetler meydana gelebilir. Son yıllarda, ekonomik, sosyolojik, çevresel ve fiziksel kırılganlıkların artmasıyla özellikle gelişmekte olan ülkelerde, afetler daha sık yaşanmaya başlamıştır. ISDR 2015 raporuna göre; dünyada afetlerden kaynaklanan maddi hasarın yıllık ortalama 314 milyar ABD dolarına ulaştığı tahmin edilmektedir. Son 10 yılda sadece meteorolojik kökenli afetlerin sayısı \% 14 oranında artmıştır. Afetlerin olası etkilerini azaltmak; ancak başarılı bir afet risk yönetimi ve toplumun afetlere karşı direncinin artırılması ile mümkün olabilecektir. Toplumda afetlere karsı direnç az, zarar görebilirlilik /kırılganlık fazla ise, afet oluşumu ve afetlerin olası etkilerine maruz kalmak kaçınıImaz olur. Bu makalede afet dirençliliği kavramı irdelenmiş ve UNISDR tarafından gündeme getirilmiş olan HFA ve Sendai Eylem planları çerçevesinde, toplumda afetlere karşı direncin artırılması için yapılabilecek çalışmalar değerlendirilmiştir.

Anahtar Kelimeler: Dirençlilik, afet risk yönetimi, Hyogo Eylem Planı, Sendai Eylem Planı

\section{Community Resilience Against Disasters}

\begin{abstract}
Disasters effects daily life and can lead loss of life and property, and destabilize the human environment. When combined with natural or technological hazard, risk and vulnerability, destructive disasters may occur. In recent years, with increasing economic, sociological, environmental and physical vulnerabilities, disasters have begun to occur more frequently, especially in developing countries. According to ISDR 2015 report; it is estimated that the property damage caused by disasters in the world reaches an average of 314 billion US dollars annually. In the last 10 years, only the number of meteorological disasters has increased by $14 \%$. Reducing the possible effects of disasters can be possible with a successful disaster risk management and with increasing disaster resilience. If the disaster resilience is low in the society and the vulnerability is high, it is inevitable to be exposed to the disasters and its destructive effects. This article examines the concept of disaster resilience and assesses the work that can be done to increase disaster resilience in society in the framework of the HFA and Sendai Action Plans, which have been brought to the agenda by UNISDR.
\end{abstract}

Keywords: Resilience, Disaster Risk Management, Hyogo Action Plan, Sendai Action Plan

\footnotetext{
${ }^{1}$ Ankara Üniversitesi, Beypazarı MYO, Acil Durum ve Afet Yönetimi Bölümü, nehir.varol@ankara.edu.tr

${ }^{2}$ Kocaeli Üniversitesi, Eğitim Fakültesi, Matematik ve Fen Bilimleri Eğitimi Bölümü, bulus@kocaeli.edu.tr

*ilgili yazar / Corresponding author: nehir.varol@ankara.edu.tr

Gönderim Tarihi: 17.11.2017

Kabul Tarihi: 21.11.2017
} 


\section{GiRiş}

"Resilience" kavramı henüz afetlerle ilişkili literatürde anlam açısından görüş birliğine varılmış bir terim değildir. Ülkemizde de; bazı kaynaklarda esneklik, bazı kaynaklarda dirençlilik olarak kullanılmaktadır. Ama son yayınlarda dirençlilik kavramı yerleşmeye başlamıştır. Afet direncini birçok araştırmacı farklı şekillerde tanımlamıştır. UNISDR 2009, tanımlamasına göre; afetlerde dirençlilik; bir tehlikeye maruz kalmış bir sistemin ya da toplumun, temel yapılarının korunması ve yenilenmesi de dahil olmak üzere, tehlikenin etkilerini zamanında ve etkili bir şekilde soğurma, eski hale dönüş ve iyileşme kabiliyetidir. Tainter ve Taylor (2014), dirençliliği, gerilemeden kurtulma yeteneği olarak tanımlamışlardır. Manyena (2009) ise; afet direncini "afetler sonrası ilerleme" ve sürdürülebilir kalkınmanın devam ettirilebilme yeteneği olarak tanımlanmıştır. Afetlere karşı direnç, sürdürülebilir kalkınma hedeflerine ulaşılmasına da katkı sağlamaktadır. Harrison ve Williams, 2016'ya göre; dirençlilik; genel bir sistemin, akut veya kronik bir strese ters yönde tepki vermesiyle, yeni bir denge durumuna erişebilme yeteneğidir. Çalışmalarında; Konfüçyüs'ün (M.Ö. 551-479) "Rüzgarda kıvrılan yeşil kamış, bir fırtınada kırılan meşeden daha güçlüdür" sözünü dirençlilik kavramını pekiştirmek için kullanmışlardır. Özetle; dirençlilik bir topluluğun ve sistemin sosyolojik, psikolojik ve fiziksel kapasitesi ile, afetlerin ve acil durumların üstesinden gelebilme, en az zararla atlatabilme ve denge durumuna tekrar ulaşabilme yeteneğidir.

Afetlerde dirençlilik bireysel ve çevresel faktörlerle yakından ilişkilidir. Cutter vd. 2008, oluşturdukları modelde; sosyal, doğal ve inşa edilmiş çevrede içinde doğal direnç ve doğal kırılganlık olan çoklu sistem, bir olayla karşılaştığında başa çıkabilme kapasitesinin varı̆ı̆ına ya da yokluğuna göre bu olayın tehlike boyutunda kalabileceğine ya da afete dönüşebileceğine işaret eder. Afetler karşısında bu etkiyi soğurabilme yeteneği dirençle alakalıdır ve soğurma kapasitesi aşılırsa, etkilenme düzeyi bu dirençliliğe göre yüksek veya düşük olacaktır. Hazırlık ve zarar azaltma süreçlerinin varlığı, yokluğu ya da etkinliği dirençliliği etkileyecektir.

Liu vd., 2017, üç katmanlı küresel yapılar yoluyla dirençliliği tanımlar. Çekirdek direnç, zaman içinde nispeten statik kalmış olan ve bireyin psikolojik, fiziksel özelliklerine ve cinsiyetine dayanan fizyolojik temeline odaklanır; içsel direnç, bireyin bireysel özelliklerinin yanı sıra, ailevi özellikleri, arkadaş çevresi, eğitim durumu ve sosyal çevresi ile ilişkilerine dayanan direncini temsil eder. Dışsal direnç ise bulunduğu ortamın çevresel coğrafik özellikleri, sosyoekonomik durumu, kurumların ve altyapıların durumu, ulaşım vs. gibi birçok dış etkene bağlı olarak gelişen direnci temsil eder (Şekil 1). Bu kavramlardan yola çıkarak, toplumun afetlere karşı direncinin bireysel özelliklerinden başlayarak, yaşadığı ortam özelliklerine kadar genişleyen birçok faktörün ve disiplinin etkisinde şekillendiği söylenebilir.

Afetlerde dirençlilikten bahsederken; kırılganlık (vulnerability) kavramını da iyi algılamak gerekmektedir. Dirençlilik ve kırılganlık birbirlerinin karşıtı kavramlar gibi görünseler de bazı durumlarda farklılık gösterebilmektedir. Kırılganlık; bireyin, topluluğun veya sistemlerin tehlikelerin etkilerine duyarlıı̆ını, hassasiyetini arttıran fiziksel, sosyal, ekonomik veya çevresel faktörlerdir. Ancak genel anlamda şunu söyleyebiliriz ki; bir toplumun ya da bireyin afetlere karşı dirençliliği ne kadar fazlaysa ve kırılganlığı az ise; afetlerle başa çıkabilme 
kapasitesi o oranda yüksektir. Karmaşık sistemlerde ise etkin bir afet risk yönetimi ve zarar azaltma çalışmalarıyla, toplumun ve sistemin direncinin artırılması ile mümkün olabilecektir.

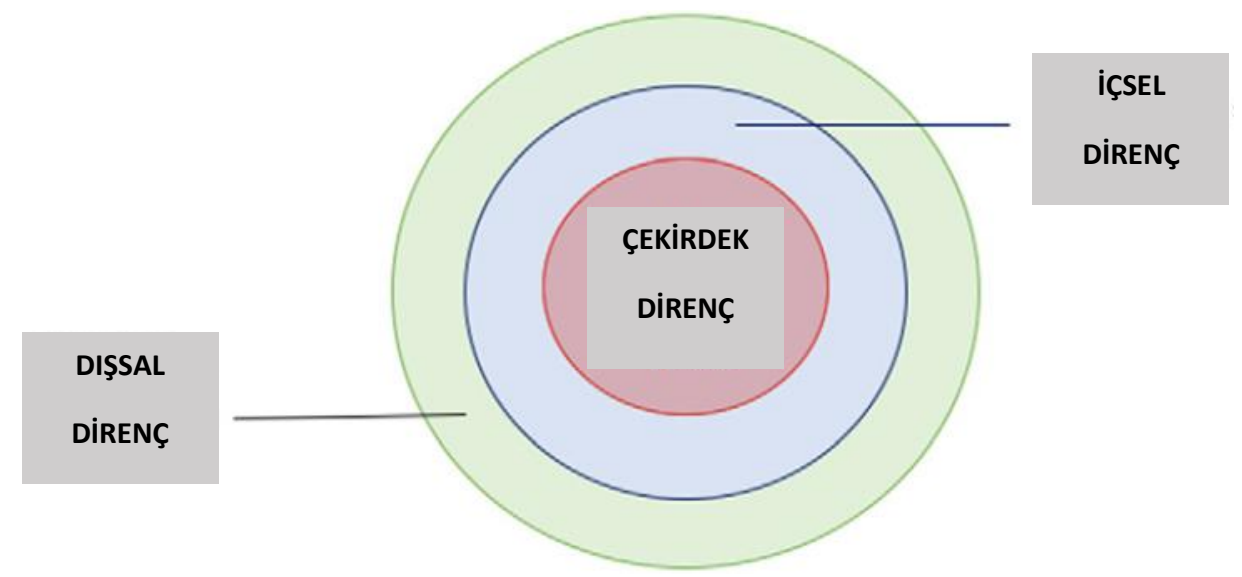

Şekil 1. Dirençliliğin çoklu-sistem (MSRM) modeli (J.J.W. Liu vd., 2017).

\section{HYOGO AND SENDAI EYLEM PLANLARI VE DİRENÇLİLIKK}

Afet risk yönetimi kapsamında, afet zararlarının azaltılması ve toplumun afetlere karşı direncinin artırıması amacı ile; belirli dönemlerde hükümetler ve kuruluşlar tarafından yol haritaları belirlenmektedir. Bu yol haritalarının en kapsamlısı ve afet risk azaltma (DRR) odaklı olanı 2005-2015 dönemi için hazırlanmış olan; Hyogo Eylem Planıdır. Daha sonra bu sürecin devamı niteliğinde olan Sendai Eylem Planı (2015-2030) yayınlanmıştır.

Son yıllarda, afetlere ilişkin yapılan çalışmalarda, kırılganlık yaklaşımı yerine, dirençlilik yaklaşımına doğru bir eğilim görmekteyiz. Afetlere müdahale aşamasına odaklanmaktan daha çok önleme, hazırlık ve zarar azaltma kavramı vurgulanmakta ve teşvik edilmektedir. Bu yönelimler, uluslararası boyutta UNISDR önderliğinde, 2005 yılında yayınlanan, Hyogo Eylem Planı çerçevesinde yaygınlaşmaya başlamıştır. Yine, 2015 yılında yayınlanan Sendai Bildirgesinde de kırılganlık kavramından daha çok dirençliliğe vurgu yapılmıştır (Uekusa ve Matthewman, 2017). Böylece, afetlerde dirençlilik, daha etkin ve etkili afet risk azaltımı (DRR) stratejilerinin geliştirilmesi için en önemli kavram haline gelmiştir.

Bu eylemlerin ve bildirimlerin nihai hedefi, toplulukların ve ulusların afetlere karşı direncini artırmak ve sürdürülebilir kalkınmayı sağlamaktır. 162'den fazla ülkenin onayladığı ve 2005 yılında kabul edilen Hyogo Çerçeve Programı (HFA), afet risklerinin azaltılması konusunda eylemlerin tanımlandığı bir uluslararası plandır (UNISDR, 2005). HFA, afet zararlarının azaltılmasına yönelik 5 öncelikli eylem sunmaktadır;

1. Afet Risklerinin Azaltılması konusunun hükümetlerin öncelikli eylem planı olması;

2. Risklerin belirlenmesi, değerlendirilmesi ve izlenmesi, erken uyarı sistemlerinin geliştirilmesi,

3. Mümkün olan her türlü bilgiyi kullanarak direnç kültürünün oluşturulması ve farkındalığın artırılması,

4. Uygun ve etkin risk yönetimi teknikleri ile risklerin azaltılması,

5. Etkin bir müdahale için hazırlıklı olunması. 
Afet riskinin azaltılması odaklı, farklı sektörler ve aktörler için ayrıntılı bir çalışma planı hazırlayan ilk küresel strateji olan HFA'nın on yıllık planının 2015'te sona ermesi ile 18 Mart 2015 'te Sendai Bildirgesi yayınlanmıştır. Sendai Bildirgesi; 187 Birleşmiş Milletler üyesi tarafından, Dünya Afet Risklerinin Azaltıması Konferansı'nda kapsamlı müzakereler yapıldıktan sonra kabul edilen gönüllü bir sözleşmedir. HFA'e oranla sağlık, iklim değişikliği ve sürdürülebilir kalkınma konuları üzerinde daha fazla vurgu yapmaktadır (Aitsi-Selmi vd., 2016).

Sendai Bildirgesi (2015-2030) bilgi, inovasyon (yenişim), eğitimdeki mevcut boşlukların incelenmesi ve afetlerde direnç eğitiminin tüm seviyelerde etkili bir şekilde uygulanması için çözümler önermektedir. Bu küresel yol haritaları ışığında, ülkeler afet risk yönetim sistemlerini yeniden gözden geçirmeli, tehlike ve risklerini belirlemeli, toplumun farkındalık seviyesini artırarak, afetlerde işbirliğine önem vererek ve risk azaltma stratejilerini her seviyede uygulayarak olası afetlere karşı hazır bulunmalıdırlar. Dolayısıyla afetlere karşı dirençli toplum ve dirençli sistemleri yaratmalıdırlar.

Türkiye, bu uluslararası stratejileri ilk onaylayan ülkeler arasındadır. HFA eylem planı sonrasında ülkelerden oluşturulması istenilen Ulusal Platformunu (NP for DRR) 2011 yılında kurmuştur (17 Ocak 2011 tarihli 2011/1320 No.'lu Bakanlar Kurulu Kararı, Resmi Gazete No. 27844, 12 Şubat 2011). Halen, AFAD koordinasyonunda faaliyetlerini yürüten Ulusal Platform, kamu kurumları, üniversiteler, yerel yönetimler, sivil toplum örgütleri, meslek odaları, medya kuruluşları ve özel sektörden toplam 53 paydaş içermektedir. Ulusal Platform, Mart 2014'te geniş katılımlı bir toplantı düzenlenmiş ve Platform Üyelerinin katkıları ile "HFA Ulusal İlerleme Raporu (2013-2015)" hazırlanmıştır.

Afet Risklerinin Azaltılması Ulusal Platformunun yeni yapısını da belirleyen önerileri 2015 yılında kabul edilmiş, ancak henüz yürürlüğe konmamıştır. Önerilen değişiklikler, Sendai Bildirgesinin de uygulanması için kolaylık sağlayacaktır. Türkiye, önleme, zarar azaltma, hazırlıklı olma ve zarar görebilirliğin azaltılmasıyla ilgili faaliyetlerini, yine Sendai Bildirgesi Çerçevesinde tavsiye edilen sürdürülebilir kalkınma politikaları ve planları, kendi afet risk yönetimi planlarına entegre edecektir.

\section{TÜRKIYEDE AFETE DIRENÇLI TOPLUM OLUŞTURMA ÇALIŞMALARI}

1999 yılında Marmara bölgesinin tamamını etkileyen depremler sonucunda; 18.243 kişi hayatını kaybetmiş, 48.901 kişi yaralanmış, $112.752 \mathrm{ev}$ ve işyeri yıkılmış, $263.933 \mathrm{ev}$ ve işyeri hasar görmüştür. Sonuç olarak $17 \mathrm{M} \$$ direkt ve $8 \mathrm{M} \$$ dolaylı zarar meydana gelmiştir. 1999'daki Marmara Depremleri, Türkiye Cumhuriyeti tarihinin en yıkıcı afeti olarak kayıtlara geçmiştir (AFAD, 2013a).

Depremlerin ardından ülkenin afet yönetim sistemi sorgulanmış; plan ve uygulamalara ilişkin birçok yeni yasa ve yönetmelikler kabul edilmiş, kurumsal değişikliklere gidilmiştir. Ülke, afet anı ve sonrası çalışmalar yerine, afet öncesi risk azaltma çalışmalarına ağırlık vermeye başlamış, reaktif politikalardan çok proaktif çalışmalara yönelmiştir. Afetlere karşı toplumun ve sistemin direncini artırmaya yönelik yapılan çalışmalardan bazıları aşağıda sunulmuştur. 
- JICA ve AFAD işbirliği ile Etkin Afet Risk Yönetimi Projesi için Kapasite Geliştirme Projesi,

- Türkiye Afet Bilgi Bankası Projesi,

- Bütünleşik Afet Risk Haritaları Oluşturma Projesi,

- Türkiye Afet Müdahale Planı (TAMP),

- Ulusal Kritik Altyapı, Varlıklar ve Tesis Belirlenmesi Projelerinin,

- Deprem Gözlem Şebekeleri Projesi,

- Depremde Erken Hasar Tahmin Projesi,

- Kuzey Anadolu Fayı (GONAF) Jeolojik Gözlemler Projesi,

- Afet Yönetmeliği Güncellenmesi Projesi,

- Afete Hazırlanan Türkiye Projesi,

- Türkiye'nin Afet Yönetim Stratejisi Belgesi.

- DASK zorunlu afet sigortası,

- Afet Riskleri Altındaki Alanların Yeniden Yapılanması Projesi,

- Bütünleşik Uyarı ve Alarm Sistemi (İKAS) Projesi

- Türkiye Afet Risk Azaltma Planı (TARAP)

- Afet Yanıt Planı (TAMP)

- Türkiye Afet Yönetim Stratejisi Belgesi (TAYSB),

Türkiye; afetlere karşı toplumsal ve sistemsel direnci artırmada en önemli unsurlardan birisi olan afet bilincinin geliştirilmesi konusunda çaba harcamaktadır. Kuşkusuz, toplulukların afet direncinin artırıması ve afetlere hazırlıklı olabilmeleri için her seviyede verilen afet dirençliliği eğitimlerinin büyük rolü vardır. Özellikle, yüksek öğretim kurumları bu konuda büyük sorumluluk taşımaktadırlar. $\mathrm{Bu}$ eğitimlerde disiplinlerarası bir yaklaşım gerektiği unutulmamalıdır.

Afetlere karşı dirençliliği oluşturan önemli etkenlerden birisi, bireyin ya da toplumun kendini güvende hissetmesidir. Yaşadığı bölgede tehlikelerin ve afet risklerinin farkında olmak, gerek otoriteler tarafından, gerek bireysel olarak risk azaltma çabalarının bilincini taşımak, afetlerin bir kader olmadığını, zararlarını azaltmanın mümkün olacağını bilince çıkarmak, yapılabilecekler ve nelerle baş edeceği konusunda eğitimli olmak bu güvenin ana unsurlarıdır.

Afet riski konusundaki farkındalık eğitimi ve kapasite geliştirme programları, direç oluşturma sürecinde temel faliyetlerdendir (UNISDR, 2012). Toplumun afetler karşısında dirençlilik kazanması ve afet zararlarının azaltılmasında etkin rol alabilmesinde eğitim önemli bir unsur olarak karşımıza çıkmaktadır. Sokaktaki her insanın afetler konusunda bilinçlendirilmesinin ne kadar zor olduğu bir gerçektir. Çeşitli kurumların, değişik zamanlarda bu tür işlevleri yerine getirmek için gösterdikleri çabalar küçümsenemez. Ancak bu çabaların gerçekleşmesi için ihtiyaç duyulan insan gücü ve maliyet düşünüldüğünde sürdürülebilirliğinin de bir o kadar zor olduğu anlaşılacaktır.

Kitagawa (2015) çalışmasında Japonya'da hem formal hem de informal olarak verilen afet eğitimlerinin önemini vurgulamakta ve afet güvenliğini güvenli eğitimin bir parçası olarak görmekte, afet güvenliğinin de afet eğitimi, afet yönetimi ve afet koordinasyonu ile sağlanabileceğini vurgulamaktadır. Yine aynı çalışmada, formal eğitim içeriklerinin ve afet 

vurgulanmaktadır.

Asharoseve Praveen (2015) ise, toplulukların afet riskini en aza indirmek için önleme ve afetlerin etkilerini sınırlamak için zarar azaltma ve hazırlık faaliyetlerini yürütülmesinin gerekliliklerine değinmişlerdir. Yine aynı çalışma da kurumlar tarafından bir müfredata bağlı olarak verilen doğrudan eğitimin ve kişinin kendi günlük aktivitesi aracılığıyla sağlanan dolaylı eğitimin toplumun afet farkındalığının arttırılmasındaki rolüne vurgu yapılmıştır. Bu eğitimler, sürdürülebilir kalkınmanın bir parçası olarak afet zararlarının azaltılması ve afet direncinin sağlanmasında da önemli bir rol oynamaktadır.

Hyogo Çerçeve Eylem planının kabul edilmesinin ardından birçok ülkede birçok farkı kurum ve sivil toplum kuruluşları tarafından ders/el kitapları, rehber ve posterler gibi çeşitli basılı eğitim materyalleri ile aktivite, oyun ve uygulamaları içeren basılı olmayan eğitim materyalleri geliştirilmiştir. Milenyumun başından itibaren, internet, sosyal medya kullanımı ve bilgi paylaşımının hızı gelişmesinin bir sonucu olarak afet risklerinin azaltılmasına yönelik özellikle çocuklar için geliştirilen oldukça çeşitli eğitim materyallerine erişim kolaylaşmıştır.

Ülkemizi derinden yaralayan 1999 depremleri sonrası afetlerin etkilerini azaltmak ve afet bilinci geliştirmek üzere Milli Eğitim Bakanlığı, Boğaziçi Üniversitesi, Kandilli Rasathanesi ve Deprem Araştırma Enstitüsü, Türk Kızılay'ı, üniversiteler, belediyeler ve sivil toplum kuruluşları gibi birçok kurum tarafından eğitim programları geliştirilmiştir (MEB, 2011; Sanduvac \& Petal, 2010). Ne yazık ki bu eğitimler sürdürülebilir olamamış, sosyal faaliyetlerden öteye gidememiş ve eğitim sistemi içerisine entegre edilememiştir. Karancı vd. (2005) tarafından yapılan çalışmada bu tür kısa afete hazırlık eğitimlerinin bireylerin motivasyonunu arttırdığı ancak kalıcı davranış değişikliğine yol açmadığı belirtilmektedir. Yine aynı çalışmada eğitimin olası afetlerle ilgili kaygıları azalttığı ve eğitim düzeyi yükseldikçe endişelerin azaldığı vurgulanmaktadır. Bu nedenle toplum temelli afet eğitimlerinin ve programlarının geliştirilebilmesi için bireyden topluma var olan farkındalık, tutum ve bireysel öncelik seviyelerinin bilinmesi ve bu doğrultuda tüm eğitim kademelerinde afet eğitimlerine yönelik derslerin eğitim programlarında yer alması toplumsal farkındalığın gelişmesine hizmet edecektir. 2009 yılında AFAD (Türkiye Afet ve Acil Durum Yönetimi Başkanlığı)'ın kurulması ile birlikte afet farkındalığı ve afetlere karşı hazırlıklı olma çabaları hız kazanmıştır. AFAD, Yerel Yönetimler, Üniversite Araştırma ve Uygulama Merkezleri tarafından verilen sertifika eğitim programları bu çabalara örnekler olarak verilebilir. Bu eğitimlerin bir kısmında e-öğrenme araçları kullanmaktadır. Bu eğitim programlarının hedef kitlesi genellikle bu alanda çalışan uzmanlardan oluşmakta ve eğitimin kazanımları konusunda bir ölçüm yapılmamakta ya da toplumla paylaşılmamaktadır.

Ülkemizde yüksekokul düzeyinde az sayıda üniversitede bulunan Acil Yardım ve Afet Yönetimi Bölümü ile önlisans düzeyinde Sivil Savunma ve İtfaiyecilik programlarında Sivil Savunma Korunma Bilgisi, Afet Kültürü, Acil Durum Yönetimi ve Sivil Savunma, Afet Yönetimi, Afetler ve Zararlarının Azaltılması dersleri verilmektedir. Bu bölümler afet yönetiminin müdahale evresinde aktif rol alacak eleman yetiştirmektedir. Diğer taraftan ülkemizdeki çoğu üniversitede öğrencilerin afetleri tanıma ve bireysel hazırlık kültürünü oluşturma çabalarına yönelik dersler maalesef yer almamaktadır. Oysa bir toplumu afete hazır hale getirmenin yolu bireyden başlayarak kurumsal ve toplumsal boyuta ulaşılmasıdır. 
İlk ve ortaöğretim programlarında yeterli olmasa da afet farkındalığı ve korunma kültürüne her kademede yer verilmekte ancak bu eğitimlerin yükseköğretimde kesintiye uğradığı görülmektedir. Yükseköğretim düzeyinde bu eksikliğin gidermesinde seçmeli dersler bir alternatif olabilir. Sınıf ortamında yüz yüze yapılan seçmeli derslerle daha az sayıda kişiye ulaşılabileceği düşünüldüğünde, bu seçmeli derslerin e-öğrenme araçları kullanılarak elektronik ortamda yapılması daha geniş kitlelere ulaşımasını sağlayacaktır. E-öğrenme, bilgi ve iletişim ağları kullanılarak gerçekleştirilen bir eğitim öğretim faaliyetidir (Brooks, at al, 2006; Aytac, 2000). E- öğrenme ile bilgiye istenilen yerden istenilen hızla ulaşılabilir. Buradan yola çıkarak branşları gözetilmeksizin Kocaeli Üniversitesi Umuttepe merkez yerleşkesinde afet farkındalığı ve kültürünü yayacak bir araç olarak e-öğrenme yöntemi ile düzenlenmiş 2 seçmeli ders, tüm öğrencilere elektronik seçmeli ders paketinde açılmıştır. 2011-2012 Eğitim öğretim yılından başlayarak günümüze kadar açılan bu derslere kontenjanların üzerinde bir talep olduğu gözlenmiştir. Bu talep gerek ilimizde gerekse ülkemizde yaşayan gençlerin ülkemiz afet gerçeklerinin farkında oldukları ve bu konuda bilgiye erişmeye istekli olduklarını göstermektedir (Gerdan ve Buluş Kırıkkaya, 2016).

AFAD, 2013 yılından başlayarak felaketler konusunda bilinçlendirmek ve Türk toplumunda "felaketlere duyarlı bir yaşam kültürü" yaratmak için "Afete Hazırlanan Türkiye" kampanyasını başlatmıştır. Afete Hazırlanan Türkiye temalı bu eğitim kampanyası kapsamında, "Afete Hazırlanan Aileler", "Afete Hazırlanan Okullar", "Afete Hazırlanmış İşyeri" ve "Afet Hazır Gönüllü Gençler" kampanyaları yürütülmüştür. "Afete Hazırlanan Okul" kampanyasını etkili bir şekilde yürütmek için Milli Eğitim Bakanlığı (MEB) ile bir protokol imzalanmıştır. Her okul için afet ve acil durum planları hazırlanmış ve eğitim sonrasında simülasyon çalışmaları İstanbul'da gerçekleştirilmiştir (URL-1).

Bir diğer çalışma ise "Okul Bazlı Afet Eğitim Projesi" dir. Proje, JICA ve MEB tarafından 2011 yılında başlatılmış, 2013 yııının sonlarında tamamlanmıştır. Proje kapsamında, 10 pilot ilden seçilen 80 ilköğretim okulunda, 7.000 öğretmen eğitilmiştir (URL-2).

Yapılan en yeni çalışma ise, Türk İşbirliği ve Koordinasyon Ajansı Başkanlığı (TíKA), Japonya Uluslararası İşbirliği Ajansı (JICA) ve Orta Doğu Teknik Üniversitesinin (ODTÜ), işbirliğinde "Afet Risklerinin Yönetimi ve Afete Karşı Dirençli Toplumların Oluşturulması" konulu eğitim programı oluşturulmasıdır. Bu kapsamda TIKA, JICA ve ODTÜ, sürdürülebilir kalkınma hedefleri açısından da büyük önem taşıyan Afet Risk Yönetimi ve Afete Karşı Dirençli Toplumlar yetiştirilmesi alanında her yıl iki hafta sürelerle olmak üzere üç sene süreli bir eğitim programı düzenleme kararı alınmıştır (URL-3).

Hangi düzeyde olursa olsun afet farkındalığı ve bilinci konusunda verilen eğitimler bireyin afet veya acil durum anında doğru davranış geliştirmesini olumlu yönde etkileyecektir. Sonuçta bireyin ve toplumun afetler karşısında direncinin arttırımasına katkı sağlaması nedeniyle son derece önemlidir.

\section{SONUÇLAR}

Doğa olayları sonucu oluşan afetler ve insan kaynaklı afetler her geçen gün daha çok can ve mal kaybına yol açmaktadır. Özellikle, çarpık kentleşme, hızı nüfus artışı, altyapı eksiklikleri, zayıf binalar, toplumun farkındalık seviyesinin yeterli olmayışı gibi kırılganlıkların artışı ile 
toplum ve sistem afetler karşısında daha savunmasız hale gelmektedir. Afetleri önlemek ya da az zararla atlatmak toplumun ve sistemlerin dirençli olması ile mümkündür. Afetlere karşı direncin artırılması ise bireysel, fiziksel, sosyolojik, ekonomik ve çevresel faktörlerle doğrudan ilişkilidir. Dolayısıyla afetlere karşı direncin sağlanması çok disiplinli bir yaklaşımı ve işbirliğini gerektirmektedir. Bu çalışmaların belirli bir sistematikte ve standartta olması için; uluslararası yol haritalarına intiyaç duyulmaktadır. Hyogo Eylem Planı ve Sendai Eylem Planı ülkelere bu imkanı sunmaktadır. Bu çerçevede ülkeler, öncelikle afet direnci kültürünü oluşturmalıdırlar. Bunu sağlamanın yegane yollarından birisi afet direnci eğitimlerinin her seviyede uygulanmasıdır. Direnç kültürünün artırımasına yönelik yapılan yatırımların, projelerin teşvik edilmesi, ekonomik ve sosyal refahın sürdürülebilir olmasını sağlayacaktır.

Hazırlıklı olma, zarar azaltma konularında proaktif yaklaşımlar ve etkin politikalar afetlerin maddi ve manevi olası zararlı etkilerini azaltacaktır.

\section{KAYNAKLAR}

1. AFAD Başkanlığı, (2013). Türkiye'deki Suriyeli Sığınmacılar, Saha Araştırması Sonuçları, Ankara.

2. Aitsi-Selmi A, Murray V, Heymann D, McCloskey B, Azhar El, Petersen E, Zumla A, Dar O, (2016), Reducing risks to health and wellbeing at mass gatherings: the role of the Sendai framework for Disaster Risk Reduction, International Journal of Infectious Diseases http://dx.doi.org/10.1016/j.ijid.2016.04.

3. Asharose, Saizen, I. and Praveen, K. C. S., (2015), "Awareness Workshop as an Effective Tool and Approach for Education in Disaster Risk Reduction: A Case Study from Tamil Nadu, India, Sustainability, 7, 8965-8984; doi:10.3390/su7078965.

4. Aytaç, T., (2000), "Gelecegin Öğrenme Biçimi: E-Öğrenme”, Bilim ve Aklın Aydınlığında Eğtim Dergisi, http://www.yayim.meb.gov.tr/yayimlar/sayi35/aytac.htm

5. Brooks, C., Greer, J., Melis, E. and Ullrich, C. (2006). Combining ITS and eLearning technologies: Opportunities and challenges. Lecture Notes in Computer Science, 4053. http://www.cs.usask.ca/ cab938/its2006_brooks_greer_melias_ullrich.pdf download March, 20, 2012.

6. Colin G., Harrison, C.G., and Williams, P., R. (2016), A systems approach to natural disaster resilience. Simulation Modelling Practice and Theory 65 11-31.

7. Cutter, S. L., Barnes,L., MelissaBerry, M., Burton, C., Evans E., Eric, Webb, J., (2008). A place-based model for understanding community resilience to natural disasters. Global Environmental Change18, 598-606.

8. Gerdan, S. and Buluş Kırıkkaya, E. (2016) University students assess the achievement of the e-learning outcomes of disasters and mitigation and disaster management courses. AJIT-e: Online Academic Journal of Information Technology.7(25), 1309-1581. http://www.ajit-e.org/?menu=pages\&p=details_of_article\&id=231

9. Kitagawa, K., (2015), Continuity and change in disaster education in Japan, History of Education, 44:3, 371-390, DOI: 10.1080/0046760X.2014.979255.

10. Karancı, N., Akşit, B., Dirik, G., (2005). Impact of a Community Disaster Awareness Training Program in Turkey: Dos It Influence Hazard-Releted Cognitions and Preparedness Behaviors. Social Behavior and Personality, 33(3), 243-258.

11. Liu, J.W.W., Reed, M., (2017). Advancing resilience: An integrative, multi-system model of resilience. Girard Personality and Individual Differences 111, 111-118.

12. Manyena, B., (2009). Disaster resilience in development and humanitarian 
interventions. Doctoral thesis, Northumbria University.

13. Sanduvac, Z., M. \& Petal, M., (2010) "History of School Seismic Safety in Turkey." Seminar Series on Disaster Education in the UK.

14. Tainter, J.A. \& Taylor, T.G., (2014). Complexity, problem-solving, sustainability and resilience

15. Building Research \& Information.Vol. 42 , Iss. 2.

16. Uekusa, S. and Matthewman, S., (2017). Vulnerable and resilient? Immigrants and refugees in the 2010-2011Canterbury and Tohoku disasters. International Journal of Disaster Risk Reduction, 22 355-361

17. UNISDR, (2005, March). Hyogo framework for action 2005-2015: building the resilience of nations and communities to disasters. In Extract from the final report of the World Conference on Disaster Reduction (A/CONF. 206/6) (Vol. 380).

18. UNISDR (United Nations International Strategy for Disaster Reduction). 2009. Terminology. Geneva: UNISDR.

19. UNISDR (United Nations International Strategy for Disaster Reduction). 2015. Sendai framework for disaster risk reduction 2015-2030. Geneva: UNISDR.

20. URL-1: https://www.afad.gov.tr/tr/1304/Afete-Hazir-Turkiye-Ile-5-Milyon-Kisiye-AfetBilinci-Egitimi'inden 15.09. 2017 de alınmıştır.

21. URL-2: http://okultabanliafetegitimi.meb.gov.tr/'den 15.09. 2017 de alınmıştır.

22. URL-3: http://www.tika.gov.tr/tr/haber/afet_risklerinin_yonetimi_ve_afete_karsi_direnc li_toplumlarin_olusturulmasi_egitimi-36405'den 15.08. 2017 de alınmıştır. 